\title{
Otra performatividad de la dictadura: la construcción de cuatro pueblos en el sudoeste tucumano
}

Reseña de: Nemec, D. (2019). Pueblos de la «guerra». Pueblos de la «paz». Los pueblos rurales del Operativo Independencia (Tucumán, 1976-1977). San Miguel de Tucumán: Editorial de la Universidad Nacional de Tucumán, 248 páginas.

Florencia Gandara

florencia.gandara@gmail.com

Universidad Nacional de San Martín, Argentina

Cita sugerida: Gandara, F. (2021). Otra

performatividad de la dictadura: la construcción de cuatro pueblos en el sudoeste tucumano [Revisión del libro Pueblos de la «guerra». Pueblos de la «paz». Los pueblos rurales del Operativo Independencia (Tucumán 1976-1977) por D. Nemec]. Sociohistórica, 47, e136. https://doi.org/10.24215/18521606e136

En Pueblos de la «guerra». Pueblos de la «paz» Diego Nemec estudia la creación-en el marco del denominado Operativo Independencia y como parte de sus tareas "antisubversivas"- de cuatro pueblos rurales en el sudoeste de la provincia argentina de Tucumán. A través del estudio riguroso de distintos aspectos de la construcción de estos pueblos desde su creación hasta el presente, Nemec indaga una dimensión aún poco explorada de la última dictadura militar argentina: la que vincula el rol represivo de dicho gobierno con su rol productivo, sus proyectos de sociedad y país. Por eso el libro se construye en torno a una ambivalencia: la de «la guerra» como forma de aludir y estudiar las múltiples prácticas represivas allí desarrolladas, y «la paz» como el proyecto que estos pueblos, inaugurados por altos mandos en $1977 \mathrm{y}$ bautizados con nombres de militares fallecidos durante el mencionado Operativo, representaron para sus creadores. Este libro fue realizado en base a la tesis de maestría que Nemec presentó en la Universidad Nacional de San Martín y su publicación por la Editorial de la Universidad Nacional de Tucumán se realizó en una colección que, en consonancia con el sentido general del libro, se titula "memorias en conflicto". Efectivamente en este libro Nemec aborda, desde distintas escalas, problemas que lo conducen a proponer una lectura compleja no sólo sobre la creación de estos cuatro pueblos tucumanos sino, en general, acerca 
de la última dictadura militar argentina: una lectura que va más allá del reconocimiento y estudio del uso de la violencia física y explora algunas de las estrategias llevadas adelante para producir consensos, memorias y sentidos favorables al gobierno militar.

La organización del libro contribuye a la reconstrucción de la ambivalencia estudiada. Tras una introducción y capítulo inicial, el libro se divide en dos partes tituladas, respectivamente, "Los pueblos de la «guerra»" y "Los pueblos de la «paz»". Para finalizar, el autor propone un capítulo de conclusiones. El capítulo inaugural del libro sitúa la construcción de los pueblos en el marco del Operativo Independencia. Para hacerlo, se detiene y reconstruye tanto quiénes eran los pobladores que serían relocalizados como también de qué modos se planificó y desarrolló la construcción de los cuatro pueblos. En relación con este último aspecto, en este capítulo Nemec plantea algunas de las preguntas y ejes que organizan su investigación acerca del rol político que los pueblos encarnaron, su carácter simbólico y el lugar que tuvieron en las políticas nacionales y provinciales de aquellos años. Asimismo, señala y analiza la existencia de un complejo y tensionado entramado de relaciones entre los poderes estatal, provincial y de sectores empresariales vinculados a la construcción de los cuatro pueblos.

En "Los pueblos de la «guerra»", el primer apartado del libro, Nemec reconstruye el modo en que estos pueblos se constituyeron en clave bélica. Para hacerlo toma dos ejes -que se materializan en los dos capítulos que conforman el apartado-. Por un lado se pregunta por los mecanismos destinados tanto al control físico de la población como a la creación de escenarios bélicos. Por otra parte, se dedica a analizar las representaciones en clave de guerra que operaron dentro y en torno a estos cuatro pueblos. Mediante un exhaustivo análisis de dispositivos y prácticas, Nemec rastrea cómo se pusieron en acto distintos dispositivos con los cuales se pretendía no sólo controlar a la población -sospechada de haber apoyado las acciones de la guerrilla- sino también construir una memoria estatal que legitime el accionar bélico del Ejército Argentino -y, en general, del gobierno militar- en el pasado inmediato. Así aparecen y se entraman la presencia de construcciones aleccionadoras, como podrían ser unos sugerentes tanques de agua/mangrullos de vigilancia emplazados en cada pueblo, con la producción de subjetividades que tenían por protagonista a una extendida "familia militar" que homenajeaba a "sus muertos en combate" de forma sistemática y cotidiana, combinando la teatralización del dolor por la pérdida con un discurso sobre el sacrificio altruista de los héroes, la consecuente victoria nacional sobre un enemigo amenazante y la producción de deberes por parte de la ciudadanía "en memoria de la sangre derramada".

"Los pueblos de la «paz»", la segunda parte del libro, tiene como objetivo estudiar el proyecto -de sociedad, de valores, de vida - que estos pueblos encarnaban, así como también los mecanismos empleados para producir, conservar y representar a sus habitantes, sus subjetividades y conductas deseadas. El autor encuentra y analiza, a los largo de los tres capítulos que componen el apartado, cuatro ejes o valores que se constituyeron como la base de la denominada "acción psicológica" y "acción cívica" desarrollada: el amor y la defensa de la Patria, Dios, la familia tradicional y la civilización. Nemec reconstruye, a través del análisis de discursos y medidas implementadas en los pueblos, los modos en que se proyectó una idea de nación inscripta en una genealogía patriótica que asociaba las guerras de la independencia con el pasado tucumano inmediatamente reciente y su presente. Asimismo, relaciona esa idea de nación a las representaciones de un ejército católico y un cristianismo militarizado que defendían los valores tradicionales y garantizaban supervivencia-motivos por los cuales la población les estaba en deuda-. Un ejemplo paradigmático de algunas de las operaciones y supuestos presentes en esta concepción de "paz" aparece en torno a la propiedad privada de las casas construidas, otorgada extraordinariamente a la población relocalizada. Como señala el autor, poseerla -aunque compulsivamente- generaba una deuda y subordinación tanto moral como económica. Esta deuda, por su parte, podía subsanarse justamente mediante el resguardo y apego a los valores propuestos, como se expresa por ejemplo en la práctica de los casamientos masivos realizados en los pueblos y al trabajo arduo. De acuerdo a las interpretaciones del gobierno, estas prácticas mejorarían las condiciones de vida de la población y, por lo tanto, la alejarían de cualquier proyecto que no fuera el de la Argentina 
proyectada por el gobierno militar. El autor finaliza el trabajo con una serie de reflexiones en las que, en relación con lo anterior, señala la integralidad del proyecto llevado adelante por las autoridades militares en los cuatro pueblos rurales tucumanos, así como también el lugar excepcional que tuvieron durante el último gobierno militar.

Que el proyecto de construcción de estos cuatro pueblos sea caracterizado como integral supone reconocer, además de la multiplicidad de mecanismos puestos en acto de forma simultánea y organizada, al menos dos dimensiones o niveles de destinatarios, tal como el autor explora y señala durante todo el libro. Por un lado se trata de un proyecto integral destinado a producir efectos al interior de cada pueblo, y de allí la preocupación del gobierno por la caracterización de la población y la consecuente vigilancia espacial, moral, religiosa y familiar, así como también la sistemática producción de sentidos y valores en su interior dirigida especialmente a la población relocalizada. Por otro lado, la integralidad de este proyecto -que se llevó adelante durante los primeros meses de la gestión dictatorial- estuvo destinada a presentar a estos cuatro pueblos como modelo a ser observado -e imitado- a nivel provincial y nacional tanto por los funcionarios como por la población civil. De allí la importancia que se le dio en los medios de comunicación de circulación nacional, por ejemplo, olas múltiples visitas que estos pueblos recibieron de altos mandos militares y personalidades destacadas de la escena pública y el espectáculo. En este sentido el autor se refiere a los pueblos como escenarios y vidrieras destinados a mostrar no sólo la paz producida y obtenida sino a teatralizar la "guerra ganada" -y la amenaza todavía latente-, y con ello legitimar el accionar del gobierno militar.

En relación con lo anterior, estudiar el caso de la construcción de los pueblos tucumanos prestando atención a cómo se relacionó a nivel local/provincial con el desarrollo del Operativo Independencia y a nivel nacional con el proyecto del gobierno militar, implica para Nemec recurrir a una gran cantidad de fuentes de distintos órdenes. Mientras la prensa escrita local (que se encuentra en el archivo del diario La Gaceta, en San Miguel de Tucumán) es su fuente privilegiada de información y la que lo ayuda a reflexionar sobre el modo de circulación y construcción de ciertos relatos a nivel local y provincial, también acude a la prensa escrita y a las revistas de circulación nacional para abordar una escala mayor. Asimismo, se sirve de fuentes orales y entrevistas (de producción propia),de discursos oficiales, fuentes estatales locales -como memorias de gestión o propagandas-y documentación de la Junta Militar (publicadas en prensa o presentes en archivos provinciales), como también de fuentes judiciales tucumanas (en el Poder Judicial de la Nación) y de una diversidad de fuentes provenientes de cada uno de los pueblos, que van desde registros escolares (de archivos locales) hasta fotografías (tomadas por el autor) de monumentos, cuadros y esculturas que todavía se exhiben públicamente.

A partir de su análisis e interpretación de fuentes y retomando también diálogos con la producción del campo de la historia reciente argentina, Nemec refuerza los argumentos sobre la necesidad e importancia deconstruir periodizaciones de mediano plazo. En este sentido, su investigación demuestra que la complejidad de los procesos sociales abordados no se puede restringir ni a cronologías limitadas por períodos de gobierno ni a interpretaciones generalizadas para la escala nacional que no se preocupan por las especificidades locales. Un ejemplo de ambas cuestiones puede encontrarse en su preocupación por la producción de consensos, y en particular asociada a la figura de Bussi, gobernador militar de Tucumán durante la dictadura -fuertemente vinculado al Operativo Independencia y a la construcción de estos pueblos- que continuó como figura política en la pos dictadura, ganó elecciones en democracia y ocupó nuevamente el cargo de gobernador de la provincia desde 1995. La investigación del autor tiene, en este sentido, un componente político que se expresa tanto en su periodización como en su preocupación por señalar que en estos pueblos rurales de Tucumán aún circulan subjetividades, consensos y sobre todo silencios que comenzaron a producirse durante la última dictadura militar, cuando fueron creados.

En suma, Pueblos de la «guerra». Pueblos de la «paz». Los pueblos rurales del Operativo Independencia (Tucumán, 1976-1977) es una investigación original que invita a profundizar una perspectiva de análisis que se descubre a la vez local y nacional. En este sentido, algunas de las preguntas que este libro articula y actualiza 
podrían formularse de la siguiente manera: ¿fue el caso tucumano, y específicamente la construcción de estos pueblos, un proyecto experimental del gobierno militar?, ¿en qué otros casos se podría encontrar la dimensión productiva de un gobierno que es habitualmente estudiado en relación a la represión y la destrucción que el autor también señala y analiza-? ¿Cómo se produjeron consensos y legitimaciones tanto a nivel local como nacional, y qué cronologías nos ayudan a abordarlos? Diego Nemec aborda prácticas y representaciones producidas en torno a la construcción de cuatro pueblos rurales en el sudoeste de la provincia argentina de Tucumán por un gobierno y un Ejército que se proyectaban a sí mismos como refundadores de la nación. Al hacerlo, descubre una trama que no sólo aporta conocimientos sobre estos pueblos y la dictadura en la provincia de Tucumán sino que también contribuye a complejizar caracterizaciones y preguntas sobre el período a nivel nacional. 